\title{
Vocación y andanzas caribeñas de Antonio López de Santa Anna ${ }^{1}$
}

\section{Antonio Lopez de Santa Anna and the Caribbean}

\author{
Benjamín Flores Hernández \\ y Mauricio González Esparza
}

Universidad Autónoma de Aguascalientes, México

El presente texto analiza la figura del célebre militar y hombre público mexicano Antonio López de Santa Anna en su faceta caribeña, teniendo como guía los periodos en los que el caudillo mantuvo un contacto directo con la región: desde su nacimiento, a través de sus andanzas militares y de sus diversos intentos por incidir en la política de la zona, y hasta sus emblemáticos exilios. Con esta perspectiva se aportan datos para una más cabal interpretación del significado del personaje, al relacionarlo con la historia de la zona.

Palabras Clave: Antonio López de Santa Anna; Caribe; Exilio; Caudillo; Veracruz; México decimonónico.

This essay analyses Antonio López de Santa Anna, the famous Mexican military man and politician in his Caribbean facet, studying particularly the moments when he lived and operated in the Gulf of Mexico and in the Caribbean Sea, in peace and in war, in Mexico or in the exile. With this perspective more data is given for an accurate interpretation of this personage and the contribution to the history of the zone.

Keywords: Antonio López de Santa Anna; Caribbean Sea; Exile; Veracruz; Mexican 19th Century.

1 También se pudo titular este artículo Los pasos de [Antonio] López [de Santa Anna] por el Caribe, en un homenaje al novelista Jorge Ibargüengoitia. Es cierto que en Los pasos de López — se recuerda que "López", en esa novela, es una obvia alusión al cura Miguel Hidalgo — no se hace alusión a ninguna andanza por el mar Caribe del iniciador de la independencia mexicana, mas el tema caribeño sí tiene lugar central en otra narración del escritor guanajuatense: Maten al león ( Ibargüengoitia, 1983), cuyo antagonista es un presunto dictador-caudillo epónimo de una isla de las Antillas, con ciertas características que no dejan de prestarse a las reflexiones de quien busque paralelismos de Santa Anna con otros personajes reales o ficticios del paisaje histórico-literario de aquella región, de todos los signos ideológicos: desde Simón Bolívar hasta Hugo Chávez, pasando por Toussaint Louverture, José Antonio Páez, Gustavo Rojas Pinilla, Papa Doc, Fidel Castro, Rafael Leónidas Trujillo o, en la exclusiva literatura, el coronel Aureliano Buendía y el "Héroe Niño de las Guerras de Independencia" de la isla de Arepa, Manuel Belaunzarán. 
Es de sobra conocida, aunque hasta ahora casi nunca inteligente ni cordialmente interpretada, la figura de este personaje central del México decimonónico, nacido en Jalapa en febrero de 1794 y fallecido en México en 1876.

El papel que Santa Anna tuvo en distintos episodios internos y externos de nuestro devenir es un aspecto muy recorrido por los autores, tanto en el pasado como en el presente, como se puede constatar en muy distintos discursos historiográficos. ${ }^{2}$ Mas la verdad es que, a pesar de todo el mar de tinta que se ha vertido sobre su persona, todavía queda mucho por decir para acabar de entenderlo en su compleja realidad. Tenemos la pretensión de que en este ensayo, al abordarlo desde la perspectiva de su relación con la región del Caribe, se reconsiderarán elementos indispensables para su cabal interpretación, así como también, en correspondencia, novedosos aspectos de la historia general caribeña.

Es cierto que don Antonio actuó durante su vida dentro del escenario mexicano general y podemos encontrarlo, por ejemplo, en Zacatecas o Guadalajara, e incluso su residencia en la ciudad de México, y durante buena parte de su existencia esto resulta esencial, por ejemplo durante las once veces que ocupó la presidencia de la República, o cuando a partir de allí organizaba campañas militares para afrontar amenazas extranjeras o rebeliones en su contra. Sin embargo, sus andanzas por las costas del Golfo de México y la península de Yucatán, así como sus experiencias extranjeras por varias islas antillanas y diversos lugares de la costa atlántica de Colombia y Estados Unidos, hacen muy interesante la aproximación a su figura con la perspectiva aquí propuesta. Pensamos que de este modo se matizará adecuadamente el sentido de su persona pública, aproximándolo incluso a toda una forma de ser y a un sentido del actuar de vocación supranacional y, a través de ello, francamente universal.

Reconocemos que nuestro texto es un mero primer paso para la aproximación a un tema hasta hoy no estudiado con rigor, que deberá ser complementado con la consulta de suficiente material de primera mano en repositorios mexicanos, españoles, norteamericanos y colombianos, principalmente.

2 Uno de los autores de este artículo - Mauricio González Esparza - presentó recientemente su tesis de Maestría en Ciencias Sociales y Humanidades, Área Historia, por la Universidad Autónoma de Aguascalientes, en la que hace una revisión general de la bibliografía existente sobre Santa Anna, y particularmente acerca de la manera de tratar a este personaje en la enseñanza del bachillerato. La bibliografía sobre Santa Anna, su tiempo y su significación sigue viviendo día a día, aunque en realidad no abundan en ella las aportaciones novedosas y los intentos serios de comprensión. Acerca de los temas tratados en este artículo son de mencionar, entre varias más, las obras de Delgado, 1991-1993 y Lynch, 1993. 
Hay que señalar que este enfoque caribeño no puede agotarse en la mera andanza militar o política del personaje, sino que alcanza una dimensión más profunda al considerar, por ejemplo, sus facetas de colonizador y de agricultor en la zona, así en sus haciendas veracruzanas como luego en Colombia, particularmente con el cultivo de dos productos típicamente caribeños: el azúcar ${ }^{3}$ y el tabaco.

\section{Veracruz y el Caribe}

Existen varios enfoques para la definición de lo que pueda entenderse por "el Caribe". Aquí se parte de uno amplio, que considera a la zona incluyendo no sólo la muy particular de las islas antillanas y el mar que las circunda, sino también el Golfo de México, abarcando en la costa americana desde la península de la Florida hasta las Guayanas y el norte del Brasil. ${ }^{4}$

Es indudable que la porción atlántica mexicana, particularmente la península de Yucatán, Tabasco y Veracruz, comparte una historia, una cultura y un interés muy característicos que lo relacionan con toda la región de las Antillas y aun, de una forma más amplia, hasta con la zona atlántica andaluza y portuguesa, con la consiguiente consideración de las Islas Azores y Canarias. Esto incluye tomar en cuenta determinados elementos, tales como un cierto ingrediente mulato en lo racial, unas costumbres extrovertidas, unas músicas de ritmo muy característico y hasta unas determinadas formas de hablar ¿No poseen un parecido ambiente social e incluso arquitectónico los puertos de La Habana, San Juan de Puerto Rico, Cartagena de Indias, Campeche, Veracruz y Cádiz?

Desde el punto de vista histórico, debe siempre recordarse al Caribe como núcleo inicial de la experiencia y de la vida americanas a partir del momento mismo del descubrimiento colombino de 1492, como la inicial base para la conquista y colonización española - hacia Centroamérica, Nueva España, Perú y Nueva Granada - y siempre como punto nodal en la

3 La trascendencia de la siembra de la caña y, por ende, la obtención de azúcar, convierten a este cultivo en uno de los emblemas del Caribe (ver Juárez Martínez, 2000, vol. I, pp. 33-40).

4 El nombre "Caribe" proviene de los nativos de la región que habitaban una parte considerable de la zona, a la llegada de los europeos en los siglos XV y XVI. Luego, el nombre de dicho pueblo se generalizó a toda la región. En referencia a la "Antilla" o "Antilia", recuérdese que era una isla mítica que se popularizó en Europa durante la Edad Media, y en el siglo XV fue el móvil de empresas marítimas que buscaban su descubrimiento, entre ellas la emprendida por Cristóbal Colón en 1492. Se creyó haberla encontrado en dicho mar: Véase Weckmann, 1996, pp. 30-54. 
comunicación del Nuevo Mundo con la España peninsular. No deja de resultar sintomático el hecho de que si la presencia hispana en el continente americano se inició en La Española y Cuba, todavía en el siglo XV, también fue en Cuba y Puerto Rico donde concluyó poco antes de iniciarse el XX.

Desde la perspectiva adoptada, el puerto de Veracruz y todo el Estado mexicano de tal nombre, sobre todo en su porción oriental, es indudablemente caribeño. Las notas geográficas, étnicas, históricas y culturales que vinculan a Veracruz con el Caribe son múltiples, y sobre ellas se volverá al analizar la plural relación de Santa Anna con la región. Bernardo García Martínez, apoyándose en la relación tan estrecha de Veracruz con el centro geográfico y político del país, la ciudad de México, habla de la vertiente del Golfo. ${ }^{5}$

Durante la etapa novohispana, todo el contacto entre la metrópoli y sus dependencias americanas estuvo condicionado por el paso por el Caribe. ${ }^{6}$ Así, la migración que sigue al descubrimiento da lugar al mestizaje entre los pueblos europeos, asiáticos, africanos y americanos.

Correspondientes al primer decenio del México independiente, por la época en que Santa Anna llevaba a cabo una vida todavía fundamentalmente regional, principalmente orientada hacia la costa golfocaribeña mexicana, tiempo de su gobernación en Yucatán y de la consolidación de su liderazgo veracruzano, son estas interesantes reflexiones de Eugenio de Aviraneta en sus Memorias íntimas, en las que este curioso y controvertido personaje —en mucho paralelo a don Antonio- hace hincapié en las semejanzas que encuentra entre los veracruzanos y los andaluces:

[En Veracruz] Creía hallarme en España, en Jerez de la Frontera, porque hablaban puro andaluz, con aquel ceceo que les es propio, y el andar jaque y fanfarrón. No podían negar que eran descendientes de aquellos andaluces que fueron a la conquista de Méjico con Hernán Cortés, y que luego se establecieron en las rancherías a la granjería de la cría de ganado, de donde derivan todas aquellas caserías. ${ }^{8}$

5 García Martínez, 2004. Cabe la observación de que este historiador establece la cadena caribeña sin incluir a Veracruz; sin embargo, como el mismo nombre lo indica: "cadena", Veracruz también puede ser un eslabón de ella, es decir entrar en el Caribe, puesto que la relación histórica entre dicho puerto y el Caribe trasciende hasta la época de los Austrias, con la materialización de la flota (ver Sorhegui, 2000, vol. I, pp. 21-31). Además María Justina Sarabia, al hablar sobre los caminos de la Nueva España, resalta la particularidad de las comunicaciones de la región: fueron marítimas y en concreto hacia el Golfo y, por ende, del Caribe. Ver Sarabia Viejo, 2006, pp. 97-115. .

6 No debemos olvidar que la Conquista se hizo desde las Antillas, además de que los funcionarios novohispanos siempre realizaron dicho trayecto para llegar y salir de su destino americano.

7 Martínez Montiel, 1988, p. 382. Hay que resaltar que durante los tres siglos que abarcó la época novohispana, la Audiencia de Santo Domingo perteneció al ámbito del Virreinato.

8 Aviraneta, 1906, citado en Méndez Reyes, 1992, p. 106. 
VOCACIÓN Y ANDANZAS CARIBEÑAS DE ANTONIO LÓPEZ DE SANTA ANNA

Para luego caracterizar así a esas gentes de Veracruz, los "jarochos":

El Jarocho es grave hasta en el andar, habla pausadamente y mide sus palabras. No blasfema ni echa juramentos como los demás paisanos. Con su mujer, ni casi habla; mientras come, no se dedica a trabajos mecánicos. En su Jacal o casa de paja, se figura y cree que está en un palacio, sin embargo de estar desnuda su habitación [...] Cuando el Jarocho está solo en su casa, se le ve sentado en su banquillo de madera, cabizbajo y apoyada su barbilla entre sus dos manos, en ademán de reflexionar, y en esta actitud se está horas enteras. Dos veces al día monta en su caballo a visitar sus milpas o maizales y visitar el sitio donde tiene sus ganados, caballar, boyal y cabrío, al cuidado de sus pastores, que generalmente son mulatos: sus mujeres e hijas cuidan de sus maizales, cultivándolos con jornaleros indios. ${ }^{9}$

Es de recordar que durante todo el siglo XIX el Caribe mexicano en general, y Veracruz en particular, siguió siendo en mucho el principal conducto para la comunicación del país con el mundo ya que por allí entraba y salía prácticamente todo: gente, mercancías, ideas, modas. Y así, pues, en la medida de personaje eminentemente caribeño, Santa Anna se presenta igual en sus andanzas políticas, en sus empresas agrícolas, ganaderas y comerciales y en sus periplos viajeros como una figura de mexicano vertido al exterior.

\section{Santa Anna y Veracruz (1794-1824)}

Santa Anna nació en Jalapa, que sería la capital del Estado veracruzano desde el momento mismo de la independencia, ciudad que hasta ahora guarda una estrecha relación de interdependencia con el puerto de Veracruz. No olvidemos que durante la mayor parte de la etapa novohispana las costas estuvieron casi deshabitadas, siendo los puertos como el de Veracruz poblados sólo por cuestiones comerciales, como la llegada de la flota. ${ }^{10}$ Por lo tanto, la gente se retiraba para su residencia cotidiana a mejo-

9 Ibidem, p. 107

10 Dicha agrupación de naves era el nervio motor del aparato español, no sólo en su parte hispanoamericana, ya que la flota pasaba por Santo Domingo y La Habana, de ahí se dividía siguiendo un grupo el camino a Veracruz a través de la costa yucateca, mientras el segundo grupo hacía escala en Cartagena en su ruta hacia Perú, atravesando después el istmo de Panamá. Pero el camino no terminaba ahí, sino que por medio del puerto y feria de Acapulco también se extendía el nervio político-comercial Europa-Asia, con Filipinas como el enclave español que podía llegar en el intercambio comercial hasta el mismísimo paraíso marcopoliano: China. De esto último tenemos como muestra la compra de mercurio realizada en el siglo XVII para abastecer a las minas de la Nueva España (ver Lang, 1977). 
res poblaciones, como es el caso de Jalapa. ${ }^{11}$ Así, Enrique González Pedrero nos describe dicha particularidad:

A los extremos físicos que la geografía señala entre costa y montaña y que el Barón de Humboldt registra sistemáticamente se suman los contrastes humanos, como resulta evidente comparando a la ciudad porteña con Jalapa, la capital. El puerto de Veracruz es el trópico: calor y color, luz y nublazón que opaca las cosas; grito de vida y de naturaleza, de violencia y espontaneidad, de días soleados que, de repente, estallan en inesperada tormenta para luego volver a dejar paso al sol y a la limpidez del cielo; de palabras fáciles, a flor de piel, como los olores y los colores. Jalapa, en cambio, es una ciudad más recatada que expansiva, lluviosa y fresca más que cálida; más europea, sobre todo por el paisaje que la rodea que propiamente meridional o española. Jalapa es una transición templada que introduce al altiplano, a Puebla y a la ciudad de México. Calles empinadas y sinuosas que trepan en el cerro, entre maples mexicanos, laureles de la India y una tupida vegetación que entrevera la del trópico, que hasta ahí se alarga, con la que brota en la montaña. ${ }^{12}$

E incluso agrega que el contexto de Jalapa y Veracruz afectaron de un modo particular a Santa Anna:

No es improbable que la naturaleza física y el acentuado contraste geográfico entre las tierras altas y las bajas, entre Jalapa y Veracruz, ámbitos entre los que oscilaron, en vaivenes, la infancia y la adolescencia de Santa Anna hayan influido en su idiosincrasia. Hay en su carácter un contrapunteo permanente de la pasión a la cabeza fría, del impulso a la conveniencia calculada, de la actividad organizada al juego y el desgano propio de la molicie de las tierras cálidas: su vida fue una sucesión de altibajos que evocan curiosamente el trasiego constante de una infancia y una adolescencia compartidas entre la serranía templada y la costa, húmeda y tropical. ${ }^{13}$

La niñez de nuestro personaje transcurre en la propia Jalapa, donde viera la luz el 21 de febrero de 1794. En 1810 inicia la carrera de las armas ingresando al regimiento de infantería de Veracruz, con el cual pronto participa en sus primeras batallas, precisamente en contra de los insurgentes en el territorio de Texas. Gracias a su desempeño militar en dicha campaña y a su buena relación con el gobernador del puerto de Veracruz, José Dávila, se le asciende, al encargársele la pacificación del corazón del territorio veracruzano - Veracruz, Jalapa y Orizaba-. En 1821 se une al Plan de Iguala y cuando se instaura éste, reconoce al Imperio de Agustín de Iturbide. En Veracruz, es el encargado de recibir a Juan O Donojú, jefe

11 De hecho, Fernando Benítez (1983) la llama "entresuelo de México".

12 González Pedrero, 1994, p. 10.

13 Ibidem, p. 12. 
político superior de la Provincia de México, nombrado por el rey de España, y de hacerle ver lo irreversible del proceso independentista. Con el Plan de Casa Mata afirma su poder regional y proclama la República Federal. Durante el gobierno de Guadalupe Victoria, primer presidente, es nombrado gobernador de Yucatán.

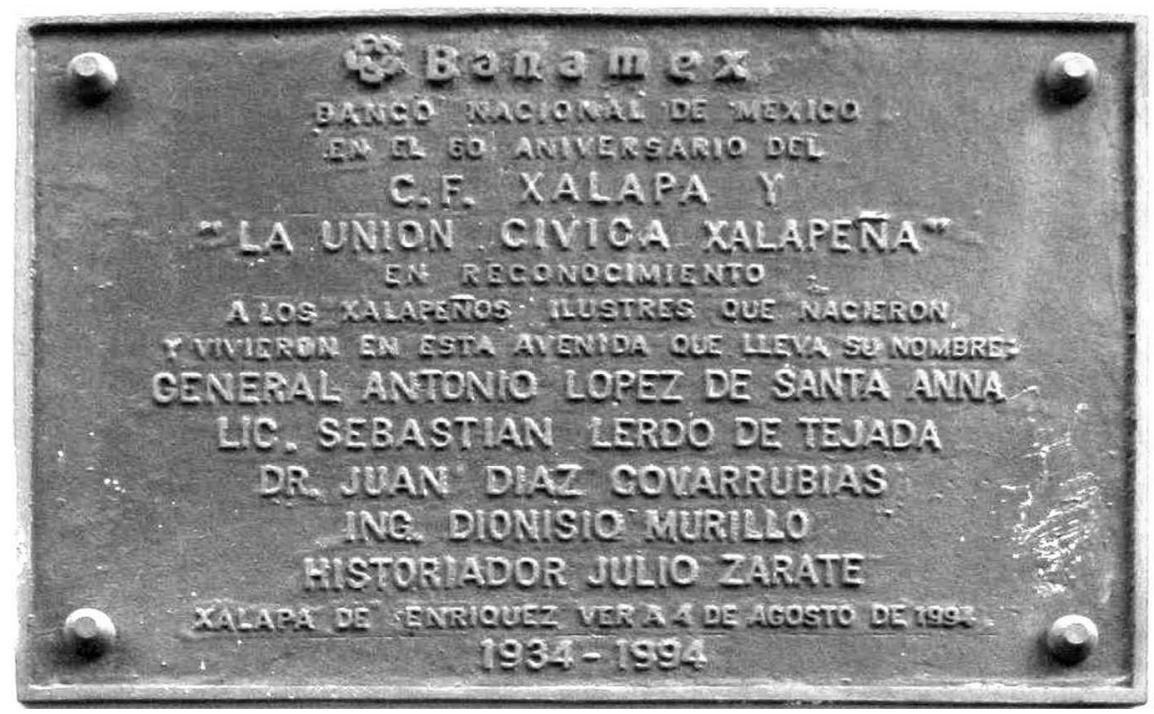

Placa conmemorativa en edificio particular del centro histórico de Jalapa

De importancia fundamental fue su labor colonizadora en Veracruz entre 1815 y 1821 . Es interesante que González Pedrero haga hincapié en el contexto geográfico y cultural en el que se desenvolvió Santa Anna entonces, con lo cual ya se anuncia el carácter tan particular que desarrolló. Aunque no lo menciona literalmente - puesto que no era su objetivoel enlace de este factor con el Caribe existe, puesto que entre líneas podemos observar cómo parte de la personalidad de Santa Anna se va asociando a ese mar, al describir el "calor y la luz..." mencionados anteriormente. Rafael F. Muñoz agrega que:

No ha vivido mal entre los "jarochos"... Cuando hay fiesta en el pueblo, se presentan a caballo, llevando en ancas cada uno una mujer, su esposa, su hermana, su novia. Las mujeres usan camisas de batista bordadas en la pechera ajustadas al cuerpo como 
una media: enaguas sutiles de gasa, encaje o batista, que transparentándose, dejan que se marque la silueta de los muslos y las pantorrillas; medias color carne, bordadas al frente, zapatos de raso y una banda carmesí o amarilla, terciada sobre el pecho. Llevan pulseras y collares de luciérnagas que parpadean, esmeraldas de la noche capturadas en los bosques. De corta talla, color moreno subido muy bien formadas, cabeza erguida, abundante pelo negro, ojos brillantes, negros, grandes; cejijuntas, boca pequeña y dientes blancos, pie chico, torneada pantorrilla, maneras desenvueltas, miradas provocativas...

Se comprende por qué el joven capitán pasó muy a su gusto... ${ }^{14}$

Y señala Enrique Krauze que el intercambio fue mutuo:

A partir de 1815, Veracruz sería su centro de operaciones. Cientos de guerrilleros amnistiados se beneficiarían del frenesí constructor de aquel teniente que fundó varios pueblos provistos de casas, calles bien trazadas, corrales, iglesias y maestros de escuela. El prestigio que cimentó desde entonces entre [esta gente] — la jarochale ganó la sólida clientela política [que] al grito de — viva Santa Anna, muera el resto- lo seguiría siempre. ${ }^{15}$

Lo anterior es muy interesante, puesto que habla de la faceta constructora del caudillo y, por ende, de la imagen positiva que generó en la gente. De hecho, él mismo lo resaltó en sus memorias:

Con la investidura de Comandante principal de la demarcación pacificada y amplias facultades, levanté pueblos, reedifiqué la villa de Medellín y todo lo organicé del mejor modo posible; en términos, que a los tres años de de paz y orden, las gentes salidas de los montes casi en estado salvaje, variaron admirablemente de índole y costumbres, manifestándose contentas. ${ }^{16}$

En síntesis y por añadidura, Santa Anna vivió durante toda su juventud y hasta el fin de su primera treintena en un ambiente casi exclusivamente caribeño, en el que el clima y la gente se encuentran fuertemente asociados con el mar, lo tropical, lo costero; del cual haría su base económica y base clientelar en las disputas políticas.

Es muy de notarse la constante actividad de Santa Anna como agricultor y colonizador en esa zona veracruzana, articulada por el camino entre el puerto de Veracruz y la ciudad de México. Allí estuvieron sus dos haciendas principales de El Encero - en las afueras de Jalapa - y Manga de Clavo — más cercana al puerto_- por lo demás dedicadas a la ganade-

14 Muñoz, 2003, p. 26.

15 Krauze, 2003, p. 129.

16 López de Santa Anna, 1967, p. 3. 
ría extensiva y a los tres cultivos esenciales de índole caribeña: el café, el tabaco y la caña de azúcar. Esa ubicación de los intereses económicos - y sociales y hasta familiares - de Santa Anna hace referencia a una clara visión geopolítica que hay que enfatizar, la cual si por una parte está preocupada por la comunicación de Veracruz y su puerto con el centro del país y su ya desde entonces megalópolis, por otra tiene siempre a la vista la natural salida de toda la nación hacia el mar —el Caribe, el Atlántico—y, a través de él y por las Antillas, hasta Estados Unidos y Europa. ${ }^{17}$ Allí, en su feudo que funcionaba como una especie de "aduana de visitantes ilustres", le tocó ser de los primeros en ver entrar y salir del país a prácticamente todos los personajes extranjeros que por allí pasaron: ya se mencionó el postrer representante regio y luego también los primeros enviados diplomáticos de las naciones "amigas", probablemente el sagaz, masón y metomentodo norteamericano Joel. R. Poinsett y, con toda seguridad, tiempo después, el español don Ángel Calderón de la Barca, cuya esposa escocesa dio cumplida cuenta de la recepción que don Antonio les dio en sus posesiones. ${ }^{18}$ En 1825 y 1826 tuvo en Veracruz amplia relación con el ya mencionado Aviraneta, el eterno conspirador vasco —al cual, según éste asegurara en su libro, le llegó a ofrecer hacerle su secretario "militar y político"-, mismo que pocos años después volvió a tener algún contacto con él cuando acompañó la expedición pretendidamente reconquistadora del brigadier hispano Isidro Barradas. ${ }^{19}$

\section{En Yucatán, la pretendida independencia de Cuba (1824-1826)}

Su paso por la región se consolidó cuando en 1824 es enviado como comandante militar a Yucatán, donde se contagió de lo particular del territorio al que no era tan ajeno, debido a lo caribeño de esa península, y entró en el juego político regional puesto que:

17 No es de olvidar que desde los tiempos virreinales el camino que venía desde Europa no terminaba en la ciudad de México, sino que se prolongaba, vía San Blas, Acapulco o Tehuantepec, por el Pacífico hasta el Extremo Oriente, a través de la nao de Manila.

18 Calderón de la Barca, 1974, pp. 25-26.

19 Aviraneta, citado en Méndez Reyes, 2002, p. 111. Santa Anna trató mucho a Aviraneta en Veracruz por 1825-1826, cuando éste militaba en las filas de la masonería escocesa para defender los intereses de los españoles residentes en Veracruz, en lo que coincidía con don Antonio, cuyo suegro era precisamente un rico peninsular establecido en ese puerto. Según afirma Aviraneta, el general Santa Anna estuvo muy cerca de pasarse a las filas de Barradas en Tampico (Ibidem, p. 88). 
Los campechanos lo festejan para atraérselo y los yucatecos lo adulan para conquistarlo. Comilonas y saraos, peleas de gallos y mestizas, en las que el comandante pierde los estribos y peca, mañana, tarde y noche. Procura balancearse entre los dos bandos. Por meses enteros tiene engañados a unos y otros. Dicta órdenes de acuerdo con las instrucciones que lleva; pero se hace de la vista gorda para que nadie le haga caso. Y prosigue de festejo en festejo, por toda la provincia. ${ }^{20}$

De dicha lucha, que él no provocó, ${ }^{21}$ saca partido y el Congreso local, para halagar a Santa Anna y traerlo definitivamente a su lado, lo nombra gobernador. En cuanto el general tuvo algún interés por los caudales que estaban en la Aduana y por los que podían ingresar, se convirtió en legislador y modificó la declaración de guerra, indicando que afectaba el comercio entre Yucatán y Cuba. Con ello se convierte en el ídolo de Yucatán. Un poeta vehemente le llama "campeón ilustre y belicoso, de Aníbal valiente fiel traslado". Y continúan las fiestas y los agasajos..22

En este contexto es en el que dirige su mirada más hacia el oriente y se encuentra con la Cuba todavía española, lugar que será temporalmente su objetivo militar:

...fue invitado por "personas respetables de la Isla de Cuba" a intentar su liberación y, cuando lo juzgó oportuno, expuso su plan al Gobierno (carta fecha en Mérida a 18 ag. 1824), diciéndole que si le enviaban dos batallones de línea, con ellos, uno que él tenía y las milicias, completaría 4,000 hombres, que creía necesarios para no aventurar la expedición... Santa Anna, dueño del campo, reuniría todos los patriotas, que esperaban con ansia su apoyo para declarar la independencia. ${ }^{23}$

La empresa se escuchaba interesante, y no hay que olvidar que los propios yucatecos y campechanos la veían con intereses económicos propios, ya que al dominar a Cuba, controlarían gran parte del Caribe. Sin embargo al final no se realizó, y desde la ciudad de México

el único que opina en favor de ella es el ministro de la Guerra, Gómez Pedraza, quien expresa su sentir en una reunión del Consejo, así:

20 Muñoz, 2003, p. 78.

21 El origen del conflicto en el que Campeche quiere separarse es desde la época novohispana, en la que regionalmente Mérida era el núcleo político hegemónico español, y quizás el único de esa península, siendo Campeche un punto de defensa subordinado a dicha ciudad, pero que se vio favorecido en función de dicho factor, ya que se convirtió en una escala importante para el convoy comercial, lo que despertó sus deseos separatistas.

22 Muñoz: 2003, p. 78.

23 Bravo Ugarte, 1982, p. 57. 
-Es una calaverada el proyecto de los habaneros. Pero si Santa Anna lo hace por su cuenta, hagámonos disimulados. Cualquiera que sea el resultado, si triunfa o si lo matan los españoles, saldremos ganando... ${ }^{24}$

Santa Anna es temerario, pero no ingenuo, puesto que al no ver apoyos concretos e incondicionales desde la capital, muda de parecer, y

don Antonio tiene muy buen olfato político. Desde Yucatán se da cuenta de todo lo que está pasando. Licencia a los marineros, libera a los levados, desarman las escalas, y se escapa de servir de alimento a los tiburones voraces de la bahía de La Habana. Además se finge lastimado profundamente en su honor por las palabras del ministro de la Guerra. Y como tiene otros planes, pide que se le releve del mando y la licencia para separarse del Ejército. ${ }^{25}$

Enrique Krauze resume su paso por Yucatán de la siguiente manera:

Desde allí, a espaldas del gobierno, haciendo siempre su real gana, planea la invasión de Cuba, propósito que si bien no realiza, contribuye a liberar al último baluarte español en México: la fortaleza de San Juan de Ulúa, frente a Veracruz. ${ }^{26}$

Aunque no aplaude el intento de independizar a Cuba, le agrega un elemento positivo: que sirvió para tomar uno de los principales puntos estratégicos de Veracruz, la fortaleza de San Juan de Ulúa, que aun se encontraba en posesión española.

Es Enrique González Pedrero quien hace mayor hincapié en el análisis del proyecto de la independencia cubana, ${ }^{27}$ donde señala que

en vez de romper con Cuba, México, desde Yucatán, podía hacer algo mucho más importante: aproximarse a la isla para favorecer su libertad, dándole un golpe definitivo a España. Semejante proyecto, de haber sido realizable, se habría vuelto uno de los actos más trascendentes, no sólo en la biografía del personaje, sino en la historia de México y del continente: le habría dado un vuelco a esa historia. Pero la independencia de Cuba en aquel momento era, aunque acaso intentable, tal vez prematura. Como lo demostraría el logro efectivo de la independencia, diferido hasta fines del siglo. Cuba no estaba aún madura. Y cuando Santa Anna lo plantea, el 18 de agosto de 1824, México no tiene recursos para precipitarla. Faltaba, por añadidura, la volun-

24 Muñoz, 2003, p. 80.

25 Ibidem.

26 Krauze, 2003, p. 130.

27 De hecho Enrique González Pedrero, en la historiografía santanista, sobresale porque a dicha empresa le dedica un apartado especial para su análisis, al que titula irónicamente "Un sueño guajiro" (González Pedrero, 1994, pp. 333-354). 
tad política. Por todo ello hoy parece evidente que se trató sólo de una fantasía que no pasó de "buen deseo". ${ }^{28}$ cubano:

Y agrega lo que pudo haber sido si se hubiera realizado el proyecto

...podría valorarse como una tesis de política estratégica de primer orden. Tenía, en verdad mucho sentido y por eso la idea de la independencia de Cuba rondó en las cabezas de mucha gente y de más de un político mexicano. Desde luego en la de Lucas Alamán, secretario de Relaciones Interiores y Exteriores del Supremo Gobierno; en la de Guadalupe Victoria, conocedor de la incipiente política exterior, en la que había participado desde Veracruz de manera importante; en la de Gómez Pedraza, secretario de Guerra y Marina y en las de muchos legisladores que integraban el Congreso Constituyente, sin olvidar algunos periodistas y a uno que otro representante mexicano de la legación en Washington. ${ }^{29}$

Se ignora qué fue lo que impulsó en el fondo a Santa Anna a tal proyecto independentista; ni sus mismos contemporáneos supieron realmente las intenciones del caudillo; nosotros, que sólo tenemos testimonios sobre el asunto, naturalmente no podemos afirmar, sólo inferir. Sin embargo, debemos coincidir con González Pedrero, quien hace hincapié en que su realización hubiera significado un cambio trascendental en la región y, por supuesto, para la historia. Además el proyecto contaba con una lógica histórica: había que alejar el factor de reconquista española. Santa Anna señaló en una carta suya que a México le correspondía el "salvar" a Cuba, y a Colombia le correspondía "liberar" Puerto Rico:

...Repito que esta obra le pertenece a la Nación Mejicana [sic] y que su empresa es digna de la magnanimidad que le distingue, así como pertenece a la República de Colombia libertar la Isla de Puerto Rico. No quedando entonces a los Españoles punto alguno en la América, no tendría ésta que temer, y podrá reorganizarse fácilmente y hacer progresos rapidísimos especialmente bajo la protección de los ingleses. ${ }^{30}$

Aparte de las suspicacias que la intentona independista produjo en la capital del país, entre las personas cercanas al presidente Victoria, la principal causa del aborto de ella fue la franca oposición que tuvo en el gobierno norteamericano del presidente James Monroe, que por lo visto ya consideraba que los Estados Unidos, en estricto apego a la doctrina por ese

\footnotetext{
28 Ibidem, p. 334.

29 Idem.

30 Ibidem, p. 338.
} 
mandatario formulada, eran los únicos destinados por la Providencia para salvaguardar la libertad de todos los americanos. Comenta Luis Chávez Orozco, en un libro que compiló sobre el tema, cómo era que entre las instrucciones que traía de su gobierno Joel R. Poinsett, primer embajador estadounidense en México, estaba la de no permitir a este país inmiscuirse en la vida cubana:

Lo cierto es que Mr. Henry Clay, en el pliego que dio a Mr. Poinsett, le decía que ejerciese una activa vigilancia sobre todos los movimientos que se hiciesen en contra de Cuba y lo autorizaba si la marcha de los acontecimientos lo exigía, para que patentizara al gobierno mexicano el criterio del Departamento de Estado, el cual consistía en que los Estados Unidos estaban conformes en que Cuba continuase en la dependencia de España. ${ }^{31}$

Así, el paso de Santa Anna por Yucatán aporta elementos para nuestro objetivo de realizar un acercamiento a este personaje y al Caribe.

\section{Años de guerra y poder. El primer exilio (1826-1846)}

La aureola de "Benemérito de la Patria" la consiguió don Antonio al encabezar, junto a Manuel Mier y Terán, al ejército mexicano en contra de la expedición española reconquistadora comandada por Isidro Barradas en 1829, también en tierras costaneras del Golfo, culminando en una acción en el puerto de Tampico. Dicha aureola y el combate político entre federalistas y centralistas convierten al caudillo veracruzano en el líder nacional y pronto en el presidente, cargo que ocupará en numerosas ocasiones aunque de manera efímera, desde su primera administración en 1833 hasta el final de la última en 1855. No hay que olvidar que hay escritores que consideran la época de 1833 a 1855 como precisamente la era santanista. Combatió en las guerras contra Texas, contra Francia - popularmente señalada como "la guerra de los pasteles" - y por supuesto en la más "dolorosa", contra los Estados Unidos.

En estos años, es de considerar particularmente desde la perspectiva aquí elegida su participación en la lucha contra los independentistas texanos, hecha a partir de la comunicación con el centro por la navegación del Golfo de México. Hasta la anécdota de su afición a masticar chicle, conta-

31 Chávez Orozco (comp.), 1971, pp. 123-126. 
giada entonces a los norteamericanos, tiene sabor caribeño, lo mismo que la fatal siesta de San Jacinto.

También tuvieron que ver con las playas del Golfo las acciones de Santa Anna durante la llamada "guerra de los pasteles". Fue frente a su querido puerto de Veracruz, en la lucha por enfrentarse al ataque galo emprendido desde la fortaleza de San Juan de Ulúa, donde sufrió la desgraciada herida que le hizo perder la pierna.

Luego, por 1841, siendo presidente de la República, llevó a cabo una acción que ratifica su interés por la comunicación de la República con el mundo a través de las costas del Golfo de México: la contratación de "el primer camino de fierro conocido en el país, el de Veracruz al interior". ${ }^{32}$

Después de poco más de una década de estar en el "subibaja" de la presidencia, es exiliado del país. Y lo que es la ironía de la vida:

Cuatro días lleva don Antonio navegando en el vapor inglés Midway...

El Morro. Habana. El hombre que quiso escalarlo y conquistarla hace veinte años, llega hoy a la sombra de sus muros y de sus palmeras en demanda de asilo.

Destierro...

¿Amargo?

¿Tranquilo? ${ }^{33}$

Al ser exiliado, acude a La Habana, en parte por la "cercanía" con Veracruz, para lo "que pudiera pasar", pero además radica en dicho lugar por el clima y costumbres que le eran agradables, lo caribeño del lugar. Incluso hay ciertas similitudes urbanas entre Veracruz y La Habana, como son el puerto, los almacenes, la aduana, las fortificaciones y el malecón, siendo ambas ciudades escala clave de la comunicación entre lo que fue la Nueva España y España. Elementos todos que hacían muy agradable su estancia; el único inconveniente resultaba no conservar la gloria, los vivas, es decir el poder.

Así, en letras de Enrique Serna, Santa Anna señala:

En La Habana, el gobierno de la isla me trataba a cuerpo de rey y por algún tiempo fui el favorito de la nobleza española...Éramos la pareja de moda en los festejos de importancia... Por si no bastara con los agasajos de la sociedad isleña, en La Habana tuve mucha suerte con los gallos...Era el hijo predilecto de La Habana. ${ }^{34}$

32 López de Santa Anna, 1967, pp. 51-52.

33 Muñoz, 2003, p. 196.

34 Serna, 2003, pp. 343 y 344. 
De tal manera que mientras en México se están dando los primeros indicios de la guerra que Estados Unidos quiere:

¿Y Santa Anna?¡Ah!;Su Excelencia, el Benemérito de la Patria, general de división don Antonio López de Santa Anna!...Allá está en Cuba, asistiendo a las recepciones de los diplomáticos, a los saraos y banquetes del capitán general...Jugando a los gallos y ganándoles a los españoles y cubanos, que conocen mucho menos que él las trampas del juego, treinta mil pesos en oro... ${ }^{35}$

\section{Desastre frente a Estados Unidos y segundo destierro (1846-1853)}

$\mathrm{Su}$ siguiente estancia en la patria no fue demasiado larga. Tras la derrota ante los Estados Unidos, consecuencia de unas campañas que también tuvieron sus episodios costeños en el Golfo, durante el avance del ejército invasor desde Veracruz hasta México, el país entra en una seria reflexión, y digamos pesimismo. Por consiguiente se necesitaban "culpables", por lo que Santa Anna inmediatamente volvió a salir exiliado y

hubiera querido vivir en Cuba, donde tenía buenos amigos, pero el nuevo gobierno presionó a las autoridades de La Habana para que me negaran asilo en la isla, y con mucho pesar me trasladé a la posesión británica de Jamaica. ${ }^{36}$

Sin embargo la caribeña Jamaica no le satisface demasiado, puesto que:

El carácter británico que predomina en Kingston es poco agradable a los Santa Anna, parlanchines, ademaneros, tropicales. El idioma es otro inconveniente. Dos años, en lugar de acostumbrarlos, les desesperan. Nuevo viaje, hacia los trópicos, hacia el lenguaje castellano y la llaneza de costumbres. ${ }^{37}$

Continúa su viaje a través del Caribe hasta llegar a la Colombia caribeña, donde

Por el recibimiento no me puedo quejar: mi fama de caudillo justiciero se había extendido hasta la Nueva Granada y la gente principal de Cartagena me entregó el corazón desde que pisamos tierra. Pero el horrible clima de la ciudad, una caldera amurallada

35 Muñoz, 2003, p. 199.

36 Serna, 2003, p. 400.

37 Muñoz, 2003, p. 241. 
donde el vapor se condensa por la falta de viento, me obligó a buscar un lugar más templado en los pueblos aledaños de la costa. ${ }^{38}$

Dicho lugar sería Turbaco. Allí, al igual que en La Habana en su primer destierro, se convierte en un personaje importante, aunque sin atribuirle los vicios cometidos en La Habana, puesto que ahora es un benefactor:

México está tan lejano, que ha dejado de ser, por el momento, una tentación. Don Antonio se aplica al trabajo, renacen las energías, el vigor, la movilidad incansable. Reedifica la iglesia adonde devotamente concurre doña Dolores, adorna los altares, completa los ornamentos, da caridad, atiende con igual sencillez a los escasos ricos y a los numerosos pobres de Turbaco que van a saludarlo, impulsa el cultivo de la caña de azúcar instalando trapiches, planta tabaco, inicia la cría de ganados, cultiva la tierra "no por la utilidad que le reporta, sino para dar ocupación a centenares de proletarios que vagaban por estos alrededores, hundidos en la miseria por no tener en qué ocuparse".

No había cementerio y S. E. lo costea, haciéndole un recinto de material. Y construye una capillita para dormir eterna y profundamente, cuando el corazón descanse. ${ }^{39}$

En Turbaco encontró un ambiente similar a Jalapa, con el puerto a poca distancia, clima tropical y vientos, pero menos insalubre y ardiente que la costa. ${ }^{40}$ No en vano se instala en la casa de Simón Bolívar, otro personaje caribeño que también deambuló por aquellas playas en busca de mejor suerte política. La estancia a la que allí dedicó sus empeños agricultores y ganaderos, trasunto de sus haciendas veracruzanas, llevó el nombre de La Rosita, en honor de su hija. Allí se volvió personaje entrañable, destacando como el artífice del desarrollo local. ${ }^{41}$

Sin embargo, si Turbaco física y culturalmente le resulta familiar al jalapeño, no puede ser lo mismo que El Encero o Manga de Clavo, esos espacios estratégicos vitales que le enseñan que el que sabe esperar encuentra una oportunidad de llegar a la cima del poder. De cualquier modo, finalmente la oportunidad llegó, y regresó a México y al mando supremo en 1853, llamado por sus incondicionales y por el partido conservador, que hasta su retiro lo fueron a buscar.

38 Serna, 2003, p. 401.

39 Muñoz, 2003, pp. 241-242.

40 Son interesantes las semejanzas entre Veracruz y Cartagena, además de las de Turbaco y Jalapa. Por principio, ambos puertos eran factores claves en la época novohispana pues, al recibir a la flota, eran la entrada y salida al mar Caribe, pero climáticamente son la crudeza del clima costero (humedad, elevadas temperaturas) y las enfermedades que conllevan. Por otro lado, Jalapa y Turbaco representan a la población de tierra adentro (Jalapa a 100, Turbaco a $12 \mathrm{~km}$ del puerto), en la que el clima es más benigno que el de la costa (Jalapa a $1460 \mathrm{~m}$. de altitud, Turbaco a 200).

41 Sobre la presencia de Santa Anna en Turbaco está el artículo de Campos, 3 de abril de 2005. 
VOCACIÓN Y ANDANZAS CARIBEÑAS DE ANTONIO LÓPEZ DE SANTA ANNA

\section{El último peregrinaje (1855-1876)}

Viene a continuación el periodo popularmente resumido como el de "su alteza serenísima", de 1853 a 1855, que fue la última vez que ejerció la presidencia. Dicho gobierno poco a poco se fue debilitando y, por principio, la muerte de Lucas Alamán le restó el más fuerte consejero y aliado. De tal manera que la oposición, encabezada por el plan de Ayutla, va derrumbándolo, y es cuando recuerda, a lo que infiere uno de sus biógrafos:

Turbaco... los plantíos de caña... el ganado que pace, indiferente a la lluvia monótona... Su Alteza piensa, sueña... Los ministros le llevan decretos para aplicar toda la crueldad de las leyes militares, no sólo a los rebeldes capturados, sino a los enemigos sospechosos. Su Alteza firma y piensa en La Rosita, en su hamaca, que se balancea suavemente... Le relatan las derrotas de sus tropas en Michoacán y San Luis Potosí, y recuerda la capilla que mandó construir para que en ella repose para siempre su incompleta osamenta.

— ¡Hay que resistir! ¡No hay que transigir! ¡Su Alteza debe continuar en el poder hasta el triunfo o la muerte!

— ¡Vayan al infierno!

A las cuatro y media de la mañana del 9 de agosto el hombre del destino sale del Palacio en su carruaje, en medio de cincuenta lanceros. ¡Al galope!

Cuando el Consejo se da cuenta, don Antonio va muy lejos, dormitando medio hundido en los almohadones de su litera.

Veracruz, el vapor de guerra Iturbide, el mar... Turbaco...42

Al iniciar el destierro en 1855 inicia un eterno peregrinaje y el ocaso de su vida política al no figurar más en el primer plano de la política nacional. ${ }^{43}$ Sin embargo, si bien el Caribe era un lugar muy agradable para él, nunca podría deshacerse de la sed de poder, así:

Dos años y siete meses. Don Antonio, todavía paciente, todavía confiado, permanece sentado en la puerta de su estancia, seguro de que verá pasar los cadáveres de sus enemigos. En cada paquebote inglés que tira sus anclas frente a Cartagena le llega un grueso atado de cartas y periódicos. Lee durante el día y escribe durante la noche. Lee que los federalistas han dictado una constitución, vigente desde el 5 de febrero de

42 Muñoz, 2003 p. 261.

43 Aunque no volverá a la presidencia, e inclusive entre 1855 y 1873 no logra conciliar más de dos meses constantes en territorio mexicano, en ciertos momentos puede advertirse que su imagen, su otrora fuerza no estaba del todo olvidada, pues al mariscal francés Aquiles Bazaine le dio temor su presencia de nuevo en el país y no dudó en expulsarlo durante la intervención francesa en 1864, e inclusive Leonardo Márquez, que parece que ya por 1859 había iniciado un movimiento a su favor en Guadalajara, ante la inminente caída de Maximiliano, es posible que haya pensado en el "héroe inmortal de Cempoala" para continuar la lucha contra los reformistas liberales. 
1857; que poco después, Comonfort, presidente de la República, la repudia, alegando que es imposible gobernar con ella y del poder pasa al destierro. Es presidente Benito Juárez, con quien Santa Anna no podría entenderse nunca: liberal, anticlerical, civilista, enemigo de las ostentaciones, silencioso y austero. Lee que los conservadores, que ya tienen nuevos caudillos, Zuloaga y Miramón, asumen el poder sin tomarlo a él en cuenta, olvidándolo como cosa perdida. Y que Juárez ha vuelto a la presidencia [...] El destierro ha revivido en él los deseos de gobernar, como el gobierno le provoca el deseo de desterrarse. ${ }^{44}$

Además de que la tranquilidad que tenía en dicho lugar se ve transgredida, lo que lo lleva a un largo ambular por el Caribe:

Una revolución estalla en Nueva Granada, acaudillada por el general Tomás C. de Mosquera. «Para librarme de las consecuencias», escribe don Antonio, se traslada a Santo Tomás, donde el viento extiende la bandera del rey de Dinamarca. Vieja ciudad de piratas, refugio de Barba Negra, de clima semejante al de Veracruz, pródiga en flores el año entero y en la que prevalece la costumbre de dormir la siesta. El viejo general, doña Dolores y los hijos, se acomodan bien en casonas del tipo español, con grandes patios que refresca el agua de las fuentes y ventanas enrejadas que miran a angostas y retorcidas callejas. Don Antonio cría gallos y escribe sus memorias, salpicándolas de simplista filosofía: «El hombre es nada, el poder es todo» y de quejas contra sus enemigos del presente: «No me han dejado un palmo de tierra, una choza en que albergarme ni una piedra donde reclinar mi cabeza ...»..$^{45}$

\section{Ahora Santa Anna se convierte en una reliquia del Caribe:}

Es el tipo pintoresco de Santo Tomás, ${ }^{46}$ el que los guías enseñan a los visitantes distinguidos, después del castillo de Barba Negra, de las murallas semiderruidas y del mercado, donde las mulatas de pecho desnudo y amplias caderas, pregonan la fruta del trópico. ${ }^{47}$

Acude a Estados Unidos, pero sin embargo no encuentra apoyo, por lo que decide jugarse una última carta: la Intervención Francesa es la excusa, y en 1864 intenta entrar al país otra vez, pero es detenido y desterrado nuevamente. No sólo los franceses lo exilian; posteriormente los republicanos, en 1867, cuando están consolidando su victoria sobre el Imperio de

44 Muñoz, 2003, pp. 261-262.

45 Ibidem, p. 262.

46 En la actualidad forma parte de las Islas Vírgenes de los Estados Unidos. El paso del caudillo no se olvida puesto que existe allí un hotel que manifiesta estar en la antigua casa de Santa Anna, de hecho lo usa en el nombre y como publicidad; su portal de Internet es http://www.villasantana.com/, consultado en marzo de 2009.

47 Muñoz, 2003, p. 265. 
Maximiliano, le detienen en Sisal y están a punto de fusilarlo, aunque finalmente lo sentencian al destierro, no sin antes hacerle pasar una temporada en las celdas de la célebre prisión de San Juan de Ulúa: escalas caribeñas. $\mathrm{Su}$ paso por esos mares no dejaba de hacer ruido, que muy bien oyeron franceses y norteamericanos. Quizás no sea casual que Veracruz y Mérida fueran dos de los últimos reductos imperialistas en capitular. ¿Hasta dónde la resistencia de Leonardo Márquez a rendirse a los republicanos en la ciudad de México, incluso después de la caída de Querétaro, tenía un cierto sustento en la esperanza de un pronunciamiento en las costas del Golfo por Santa Anna, con quien por lo demás ya había entrado en tratos Maximiliano desde los últimos meses de 1866 ?

De La Habana también lo expulsan. Brinca de una parte a otra de las Antillas. Hasta que

don Antonio López de Santa Anna se estableció en Nassau (Bahamas). Su vida no fue ya de boato. Doña Dolores, su esposa, no causaba más admiración de la sociedad. ${ }^{48}$ Conservaba las huellas de su singular belleza, su centelleante simpatía y su elegancia de finura, aunque exagerada a veces por los abusos de la encajería, de las joyas y del linaje que pretendió el viejo minero Tosta, de Zacatecas; pero como parecía un poco vuelta a la razón a causa del apartamiento de su marido en aquellas solitarias playas bahamesas, el séquito de emperejiladas jarochas, las acompañantes negras, la balumba de los mozos de cordel, en fin, todo aquel aparato que puso en desvelo a los habaneros de mediados del siglo XIX, no eran ahora gotas de las mieles de la señora Tosta. Para una dama de su alcurnia y de su incontenible pasión por las honras y dignidades a todo lo cual se ayuntaba su inagotable benevolencia, Nassau no podía ser más que un pueblo coralífero, a donde no faltaban aventureros de cuentas alegres; y tan ajeno a las tertulias y faustos era aquel lugar, que la señora Tosta resolvió trasladarse a $\mathrm{La}$ Habana, aunque ya no para hacer vida de pompa, sino a fin de dirigir desde allí la administración de sus muy mermados intereses. ${ }^{49}$

La propia versión de don Antonio en sus memorias es más bien de gratitud para con las Bahamas y su gente, las cuales sólo desea dejar al ver llegar el final de sus días:

48 La vida tan particular que llevó el caudillo en sí misma lo hace famoso, sin embargo no ocurre igual con las personas cercanas a él. Basta señalar a sus esposas, ya que de la primera, Inés de la Paz García, prácticamente no se recuerda nada; y con la segunda, Dolores Tosta, quizás hubiera pasado lo mismo, pero tuvo la fortuna de quedar inmortalizada por el pincel de Juan Cordero, quien realizó un retrato de ella. Dicha pintura es brillante y hermosa. Ésta se encuentra en el Museo Nacional de Arte en la ciudad de México. Hasta enero de 2008 estaba en exhibición, sin embargo en la actualidad está en resguardo en el almacén del museo, probablemente por "restauración". De sus descendientes, por lo demás, se ha perdido todo rastro.

49 Valadés, 1979, pp. 17-18. 
Deseando tranquilidad y seguridad, me trasladé a esta ciudad de Nassau, donde he conseguido lo que deseaba, pues he pasado cuatro años bastante contento por la generosa hospitalidad que he encontrado, y desearía terminar aquí mis últimos días entre tan simpáticos habitantes si obligaciones de familia no me empujasen al suelo patrio..$^{50}$

Agustín Yáñez resume este último destierro como:

La odisea final de Santa Anna es, humanamente, el periodo más interesante de su vida y no en vano ocupa casi la mitad de la autobiografía: registra vilipendios, fracasos, riesgos inminentes de la vida y ninguna hazaña gloriosa. Exiliado, esperanzado arrebatado por las aguas turbulentas del Golfo, que una y otra vez lo llevaron a playas contrarias, derrotado, prisionero, enfermo, el Ulises paranoico erró, durante veinte años, en acecho fiel del poder, hasta que logra volver a su tierra no para anonadar otra vez a los pretendientes de la Patria, sino para languidecer y morir ..$^{51}$

De las citas anteriores se desprende que estos años finales del exdictador fueron "el periodo más interesante" de su existencia. Así el gran Caribe nos vuelve a ofrecer la oportunidad de entrar en la vida de tan apasionante personaje.

Por fin, en 1874, después de la muerte de Benito Juárez, su gran enemigo, y cuando en la presidencia de la República está su paisano jalapeño Sebastián Lerdo de Tejada, que por lo demás ni siquiera se dignó recibirlo, ya con ochenta años encima, regresa al suelo patrio de manera definitiva, estableciendo su última morada en la ciudad de México, en la que muere el 21 de junio de 1876. Estos últimos tiempos los vive en la pobreza: con sus bienes mexicanos expropiados por el gobierno, el resto del capital perdido en las últimas aventuras, hipotecado para adquirir barcos y pertrechos con los que luchar por el poder que nunca usufructúa, la pensión de general rechazada por dignidad.

\section{Reflexiones finales caribeñas}

Es innegable la presencia de Santa Anna en el Caribe, principalmente en cinco grandes momentos: al nacer en la provincia de Veracruz en 1794, a su paso por Yucatán en 1824, y durante los tres exilios de 1845, 18481853 y 1855-1874. Así desde su nacimiento vivió, se desenvolvió y disfrutó el ambiente caribeño.

50 López de Santa Anna, 1967, p. 175.

51 Yáñez, 1982, p. 205. 
Sí bien deambuló por varias poblaciones del Caribe, en general su aferró más a la parte hispánica: la insular de La Habana y la actual República Dominicana y la continental de Veracruz, Yucatán y Colombia.

Una primera explicación de lo anterior se puede concretar en la conveniencia política de permanecer al acecho del acontecer en México. Sin embargo, esto no agota las motivaciones de nuestro hombre para buscar el continuo cobijo de las olas antillanas. Como se ha visto en páginas anteriores, a través de textos de diversos autores que se han enfocado a la vida de dicho personaje, se observa el "encanto y el gusto" por la región. Así por sus condiciones climáticas como por sus costumbres, hábitos y gustos culturales, entre ellos las peleas de gallos, las cuales aunque no nativas ni exclusivas de la región, tienen allí una enorme popularidad. ${ }^{52}$

Desde el trabajo de Rafael F. Muñoz, quien se convirtió en un referente obligado y esencial sobre el personaje, observamos la estrecha relación entre Santa Anna y el Caribe, faceta en la que el caudillo encaja con un paradigma caribeño definido literariamente por Gabriel García Márquez —originario de la vertiente caribeña de Colombia- en varias de sus novelas, muy en particular - aparte de El general en su laberinto, alusión a los últimos días de Simón Bolívar- en El coronel no tiene quien le escriba y Cien años de soledad. En la primera no cuesta trabajo captar el paralelismo entre aquel coronel gallero que no acababa de recibir la carta con la pensión a la que tenía derecho tras una vida de combate con las armas y el postrer Santa Anna, viejo y enfermo, despojado de sus bienes por los liberales y aparentemente olvidado de todos, que ha renunciado a la paga que le correspondía como general del ejército y sufriendo la pena de no poder atender adecuadamente a su sustento y al de su esposa. Respecto a Cien años de soledad, el personaje concreto cuya descripción y aventuras traen enseguida a la mente el recuerdo de Santa Anna es el coronel Aureliano Buendía, cuya existencia resume así la espléndida prosa de García Márquez:

El coronel Aureliano Buendía [-a lo Santa Anna-] promovió treinta y dos levantamientos armados y los perdió todos. Tuvo diecisiete hijos varones de diecisiete mujeres distintas [-la fama de "sultán" siempre acompañó al jalapeño-], que fueron exter-

52 Sobre las peleas de gallos, ver Sarabia Viejo, 2006. Además, uno de los autores del presente trabajo, Benjamín Flores Hernández, realizó una investigación en la UAA titulada "Los gallos. El 'ave del sol', a través del tiempo y del espacio" y de la cual se han desprendido varios artículos, aunque en su mayoría de índole regional (consultar informe final de investigación en la UAA). De todos los gallos de pelea que tuvo Santa Anna, tal vez el preferido por encima de todos fue el nombrado "Panchito" y, en segundo lugar, el "Cola de plata". 
minados uno tras otro en una sola noche, antes de que el mayor cumpliera treinta y cinco años. Escapó a catorce atentados, a sesenta y tres emboscadas y a un pelotón de fusilamiento [-como don Antonio en San Juan de Ulúa en 1867-]. Sobrevivió a una carga de estricnina en el café que habría bastado para matar a un caballo. Rechazó la Orden del Mérito que le otorgó el presidente de la república. Llegó a ser el comandante de las fuerzas revolucionarias, con jurisdicción y mando de una frontera a la otra, y el hombre más temido por el gobierno, pero nunca permitió que le tomaran una fotografía. Declinó la pensión vitalicia que le ofrecieron después de la guerra y vivió hasta la vejez de los pescadillos de oro que fabricaba en su taller de Macondo. Aunque peleó siempre al frente de sus hombres, la única herida que recibió se la produjo él mismo después de firmar la capitulación de Neerlandia que puso término a casi veinte años de guerras civiles. Se disparó un tiro de pistola en el pecho y el proyectil le salió por la espalda sin lastimar ningún centro vital. Lo único que quedó de todo eso fue una calle con su nombre en Macondo. Sin embargo declaró pocos años antes de morir de viejo, ni siquiera eso esperaba la madrugada en que se fue con sus veintiún hombres a reunirse con las fuerzas del general Victoriano Medina. ${ }^{53}$

Recordemos que Macondo, el mágico lugar utópico en que transcurren varias de las narraciones de García Márquez, hace alusión a su pueblo natal, Aracataca, en el Departamento colombiano de Magdalena, frontera natural con Turbaco.

De Antonio López de Santa Anna ¿queda, cuándo menos, en algún lugar mexicano, una calle con su nombre? Lo único suyo, para estos años iniciales del siglo XXI, es su mala imagen popular, no por inexacta e injusta menos compartida por la mayoría de los mexicanos, su interpretación como el más característico villano de nuestra historia y el funcionario corrupto por antonomasia, aquel que "vendió a los gringos la mitad de nuestro territorio". Véase, si no, la última "ópera" que acaba de estrenar Carlos Fuentes.

Quizás quienes más se han aproximado a reflexionar acerca de la faceta caribeña santanista hayan sido Rafael F. Muñoz y Enrique González Pedrero, quienes, aunque sólo muestran indicios sobre la materia, puesto que su veta principal era otra, nos han dejado el socavón para continuar avanzando en el tema.

Así nos encontramos con un personaje que en periodos concretos se empapó de la brisa del Caribe, donde buscó asilo, inspiración y, sin darse cuenta, se convirtió en una reliquia, que espera su rescate a los ojos contemporáneos. La casa en que viviera en Turbaco, en la que antes residiera el mismo libertador Simón Bolívar y que hoy es la alcaldía, aun se enseña

53 García Márquez, 2007, pp. 125-126. 
a los visitantes como la mansión de un patriarca que produjera en el lugar abundantes riquezas, hijos naturales y compadres; y la que tuvo en Santo Tomás, en las Islas Vírgenes, hoy es un hotel de lujo que lleva su nombre y una de cuyas habitaciones más exclusivas se enorgullece de haber sido la biblioteca de aquel aparente "filósofo en retraimiento" que un día visitara Madame Calderón de la Barca en su enorme y productiva hacienda de Manga del Clavo.

Recibido el 1 de abril de 2009 Aceptado el 8 de julio de 2010

\section{Bibliografía}

Eugenio de Aviraneta: Mis memorias íntimas o apuntes para la historia de los últimos sucesos ocurridos en la emancipación de la Nueva España (1825-1829), México, Moderna Librería Religiosa de José L. Vallejo, 1906.

Fernando Benítez: La ruta de Hernán Cortés, México, Fondo de Cultura Económica/Secretaría de Educación Pública, 1983.

José Bravo Ugarte: Historia de México, México, Editorial Jus, 1982.

Madame Calderón de la Barca: La vida en México durante una residencia de dos años en ese país, México, Porrúa, 1974.

Marco Antonio Campos: "El filántropo Santa Anna en Turbaco", en La Jornada semanal, 526, México, 3 de abril de 2005. Se consultó en diciembre de 2009 en http://www.jornada.unam.mx/2005/04/03/sem-anna.html.

Luis Chávez Orozco (comp.): Un esfuerzo de México por la independencia de Cuba, México, Porrúa, 1971.

Jaime Delgado: España y México en el siglo XIX, Madrid, Consejo de Investigaciones Científicas, 3 ts., 1991-1993.

Gabriel García Márquez: Cien años de soledad, Bogotá, Real Academia Española/Asociación de Academias de la Lengua Española, 2007.

Bernardo García Martínez: El desarrollo regional, siglos XVI al XX, México, Océano/UNAM, 2004.

Mauricio González Esparza: Más allá de nuestra historia tradicional. La figura de Antonio López de Santa Anna en la enseñanza de la historia en la preparatoria de la UAA y las escuelas incorporadas a ella: cómo es hoy y una propuesta alternativa, tesis para optar al grado de Maestría en Ciencias Sociales y Humanidades, Universidad Autónoma de Aguascalientes, Aguascalientes, 2008.

Enrique González Pedrero: País de un solo hombre: el México de Santa Anna, Vol. I, México, Fondo de Cultura Económica, 1994. 
Jorge Ibargüengoitia: Maten al león, Joaquín Mortiz, México, 1983.

Abel Juárez Martínez: "La Habana y Veracruz, dos confines caribeños del mundo hispánico”, en Óscar Mazín Gómez (ed.): México en el mundo hispánico, 2 ts., Zamora, Michoacán, El Colegio de Michoacán, 2000, vol. I, pp. 33-40.

Enrique Krauze: Siglo de caudillos, México, Tusquets Editores, 2003.

Merving F. Lang: El monopolio estatal del mercurio en el México colonial (15501710), México, Fondo de Cultura Económica, 1977.

John Lynch: Caudillos en Hispanoamérica 1800-1850, Madrid, MAPFRE, 1993.

Abel Juárez Martínez: "La Habana y Veracruz, dos confines caribeños del mundo hispánico”, en Óscar Mazín Gómez (ed.): México en el mundo hispánico, 2 ts., Zamora, Michoacán, El Colegio de Michoacán, 2000, vol. I, pp. 33-40.

Antonio López de Santa Anna: Mi historia militar y política. 1810-1874. Memorias inéditas, México, Editora Nacional, 1967.

Luz María Martínez Montiel: "Veracruz en el Caribe", en Cultura del Caribe. Memoria del Festival Internacional de Cultura del Caribe, Secretaría de Educación Pública, México, 1988.

Salvador Méndez Reyes: Eugenio Aviraneta y México. Acercamiento a un personaje histórico y literario, México, UNAM, 1992.

Rafael F. Muñoz: Santa Anna. El dictador resplandeciente, México, FCE, 2003.

María Justina Sarabia Viejo: "Los caminos del Golfo de México", en Chantal Cramaussel (ed.): Rutas de la Nueva España, Zamora, El Colegio de Michoacán, 2006, pp. 97-115.

- Las peleas de gallos en América. Su historia, tradición y actualidad, Editorial Real del Catorce/Limusa, Madrid/México, 2006.

Enrique Serna: El seductor de la patria, México, Editorial Joaquín Mortiz, 2003.

Arturo Sorehgui: "Relaciones entre Nueva España y La Habana", en Mazín Gómez (ed.): México en el mundo novohispano, Zamora, 2000, vol. I, pp. 21-31.

José C. Valadés: México, Santa Anna y la guerra de Texas, México, Diana, 1979.

Luis Weckmann: La herencia medieval de México, México, Fondo de Cultura Económica/El Colegio de México, 1996.

Agustín Yáñez: Santa Anna, espectro de una sociedad, México, Océano, 1982. 


\section{Apéndice. Santa Anna y el Caribe en tres mapas}

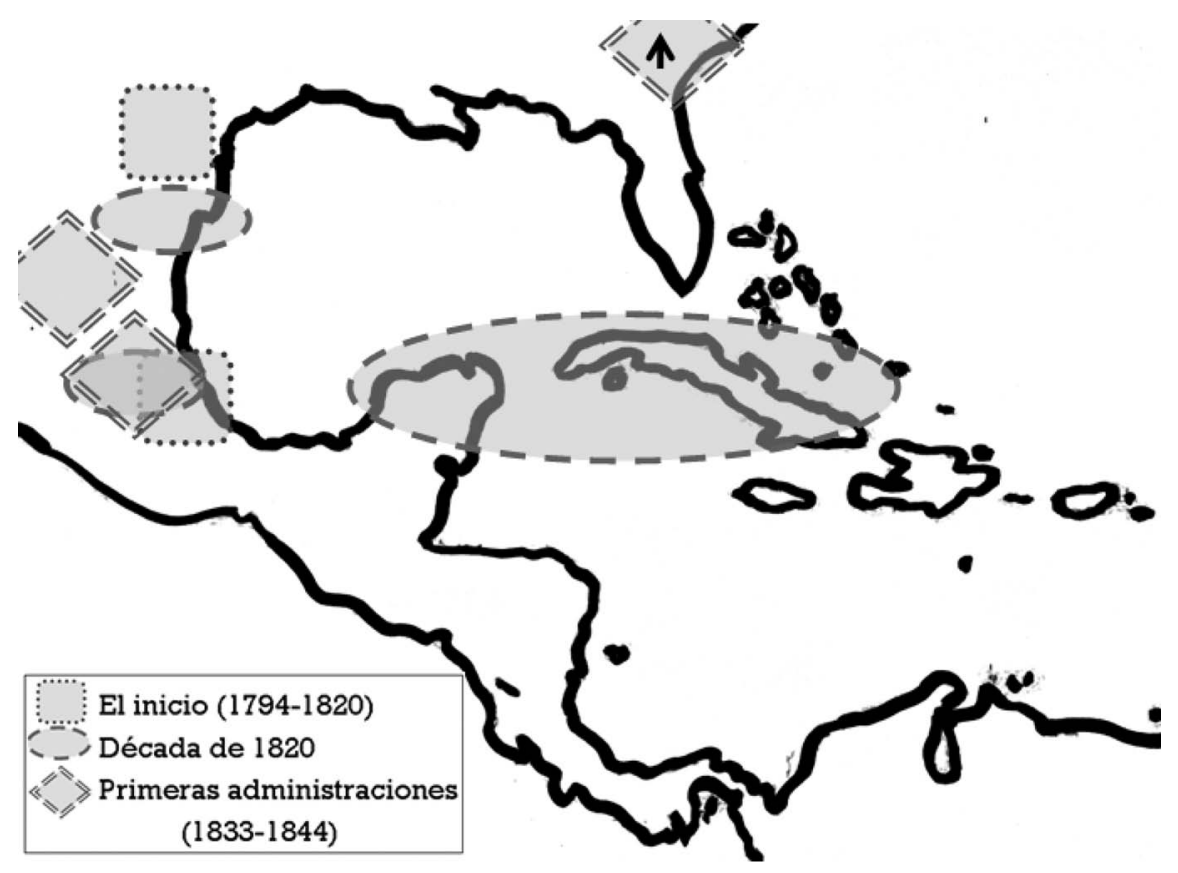

El inicio, 1794-1820: 21 de febrero de 1794 nace en Jalapa, Veracruz; 1810 ingresa al ejército; 1813 campaña contra los insurgentes en Texas; 1816-1820 contra los insurgentes en Veracruz.

Década de 1820: 1820-1823 Ciudad de México y Veracruz; 1824-1825 Yucatán —plan de independencia de Cuba-; 1825-1828 Veracruz, Tulancingo; 1829 Tampico, Veracruz.

Primeras administraciones 1833-1844: 1833-1835 Ciudad de México, Veracruz; 1835 Querétaro, Aguascalientes, Zacatecas, hacia Texas: San Luis Potosí; 1836 Coahuila, Béjar, San Jacinto; 1837 Texas; 1838 Ciudad de Washington, Veracruz; 1839-1844 Ciudad de México, Veracruz. 


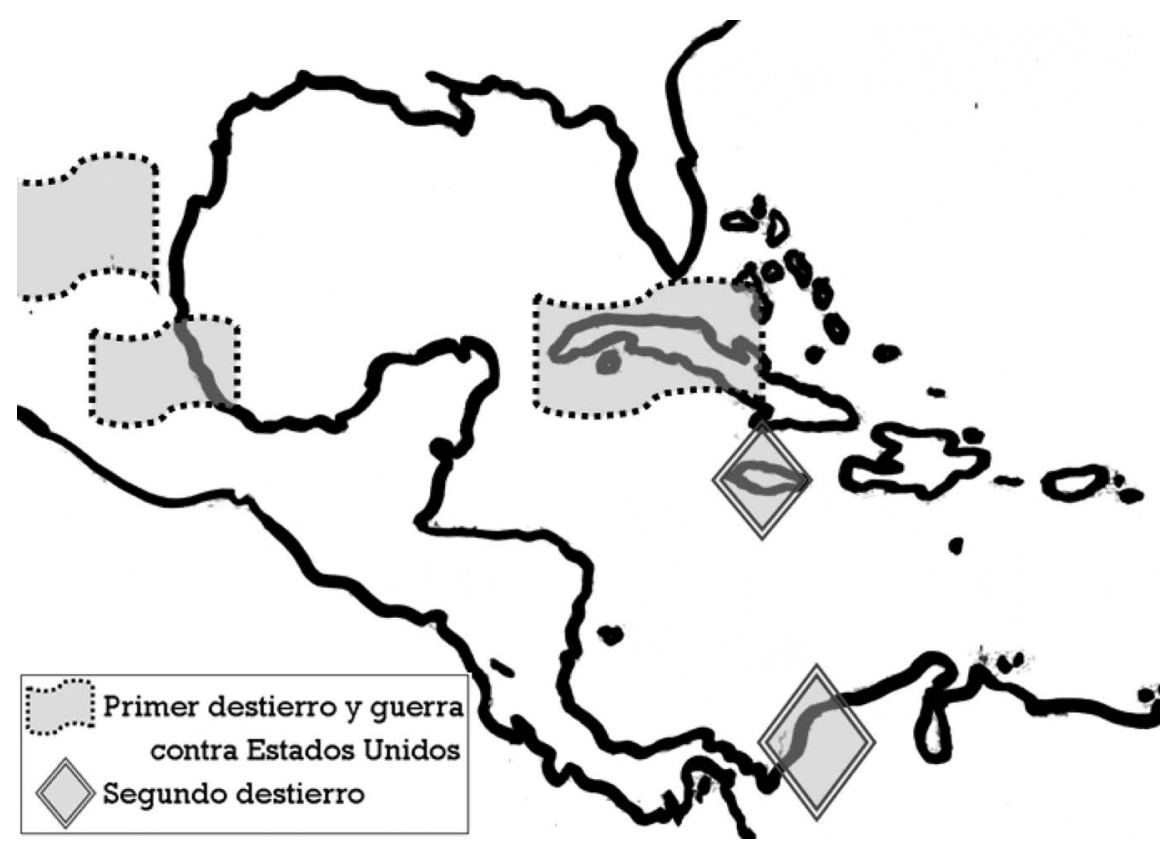

Primer destierro y guerra contra Estados Unidos: 1845 La Habana; 1846 Veracruz, San Luis Potosí, Coahuila; 1847 Veracruz, Ciudad de México, Puebla. Segundo destierro: 1847-1853 Jamaica y Turbaco. 


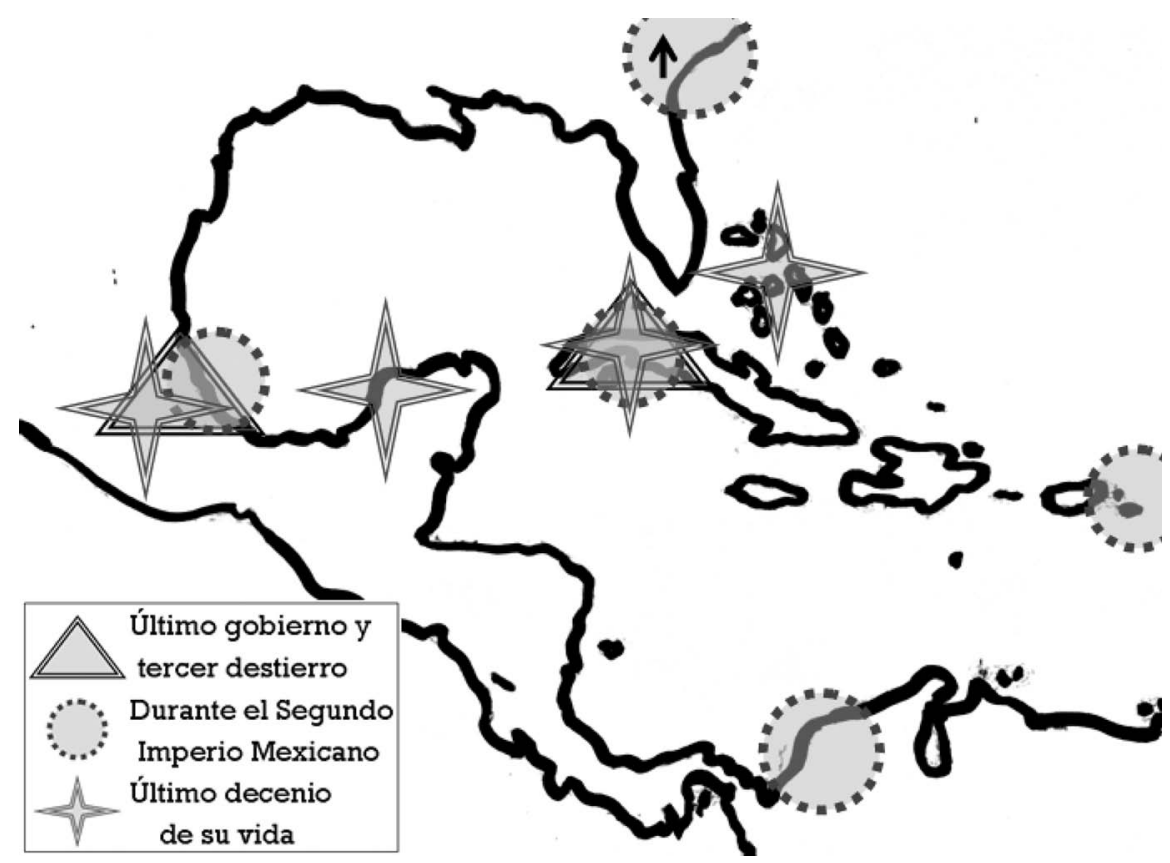

Último gobierno y tercer destierro: 1853-1855 Veracruz y ciudad de México; 1855-1864 Cuba y Turbaco.

Durante el Segundo Imperio Mexicano: 1864-1867 Veracruz --expulsado por Bazaine--, La Habana, Turbaco, San Thomas, Nueva York.

Último decenio de su vida: 1867-1874 Veracruz, Sisal, La Habana, Nassau; 1874-1876 Ciudad de México, muere 21 de junio. 